\title{
External Fixator Distraction Idea to Reduce Complex Digital Fractures and Preserve Digital Joints
}

ISSN: 2576-8875

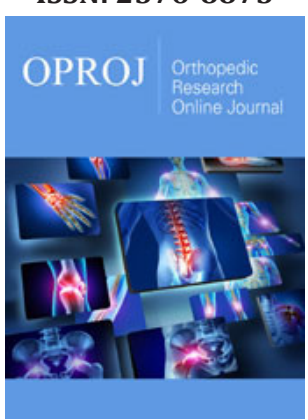

${ }^{* 1}$ Corresponding author: Ahmed Mokhtar Mahmoud Elbayer, Doha

Submission: 毕 May 06, 2019

Published: 監May 10, 2019

Volume 5 - Issue 4

How to cite this article: Ahmed M M E* Habib A, Iqbal W, Sohail Q ,Ahmed Mofeed M. External Fixator Distraction Idea to Reduce Complex Digital Fractures and Preserve Digital Joints. Ortho Res Online J. 5(4). OPROJ.000617.2019.

DOI: 10.31031/OPROJ.2019.05.000617

Copyright@: Ahmed Mokhtar Mahmoud Elbayer, This article is distributed under the terms of the Creative Commons Attribution 4.0 International License, which permits unrestricted use and redistribution provided that the original author and source are credited.

\author{
Ahmed Mokhtar Mahmoud Elbayer*, Habib Al-Basti, Iqbal Wani, Sohail Quazi \\ and Ahmed Mofeed Mokhallalati \\ Hamad Medical Corporation, Doha
}

\begin{abstract}
Complex digital fractures are so challenging to treat sometimes. Especially those involve digital joints surface, in this work we will illustrate how to tackle such fractures with minimal steps

Keywords: Digit; Digital; Fractures; External; Fixator; Distraction; Complex; Fracture; Joint; Joints; Reduction; Fixation; K wire; K wires; Kirschner wire; Kirschner wires; Hand; Thumb; Index; Middle; Long; Ring; Little; Metacarpal; Plate; Screws; Prosthesis
\end{abstract}

Abbreviations: K wires: Kirschner Wires; AP: Anteroposterior

\section{Introduction}

Digital Fractures are challenging to treat especially when it involves more than one joint surface, more than one phalanx and a lot of small pieces. These fractures usually happen with massive compression force, setting varies between work, sport injury or even road traffic accidents.

They are a lot of modalities to treat such fractures, eg. splinting without surgical intervention due to the complexity of the fracture with a later joint prosthesis if needed. Other modalities include open reduction with trial of fixing small pieces together which is impractical [1].

\section{Case Presentation}

17-year-old male had a rollover car accident, presented with isolated little finger comminuted fractures proximal and middle phalanx involving the joint surface for each (Figure 1)
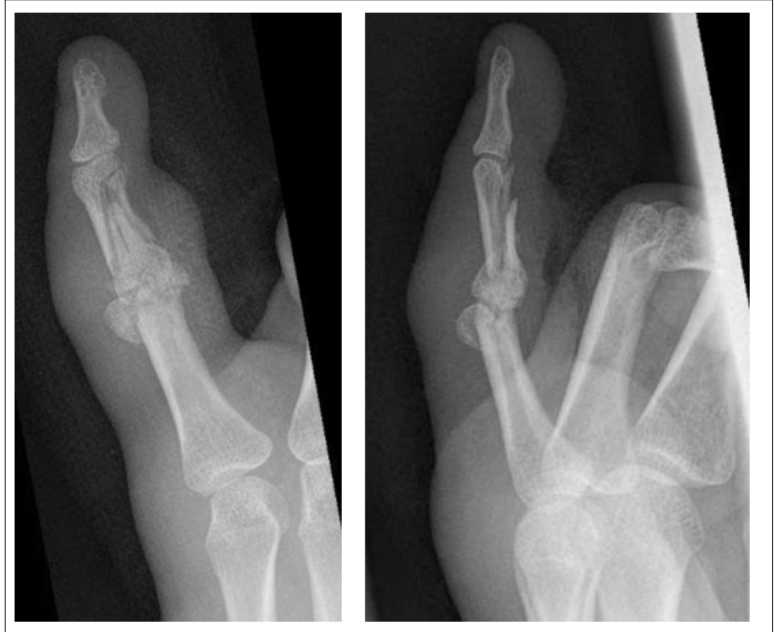

Figure 1: AP and Lateral views for little finger proximal and middle phalanx comminuted fracture. 


\section{Intraoperative}

We decided to use External fixator to distract the fracture pieces with manual compression of the fractured phalanx to reduce the pieces under fluoroscopy.

a) Inserted the proximal pin first in the proximal phalanx shaft

b) Insertion of the distal pin in the distal phalanx (away from the fractured middle phalanx)

c) Xrays done to adjust the position and the depth of the pins

d) Insertion of the external fixator device on both pins. e) Before tightening the clamps, application of distraction force done between the two pins by pulling the distal pin as maximum as possible with one hand and fixing the clamps using clamp drivers in the new position.

f) Xray is done shows great reduction of the fractured pieces

g) Reduction of the bicondylar proximal phalanx done using bone holder clamp

h) Insertion of transverse. $8 \mathrm{~mm} \mathrm{k}$ wire

i) Xray taken (below) (Figure 2)

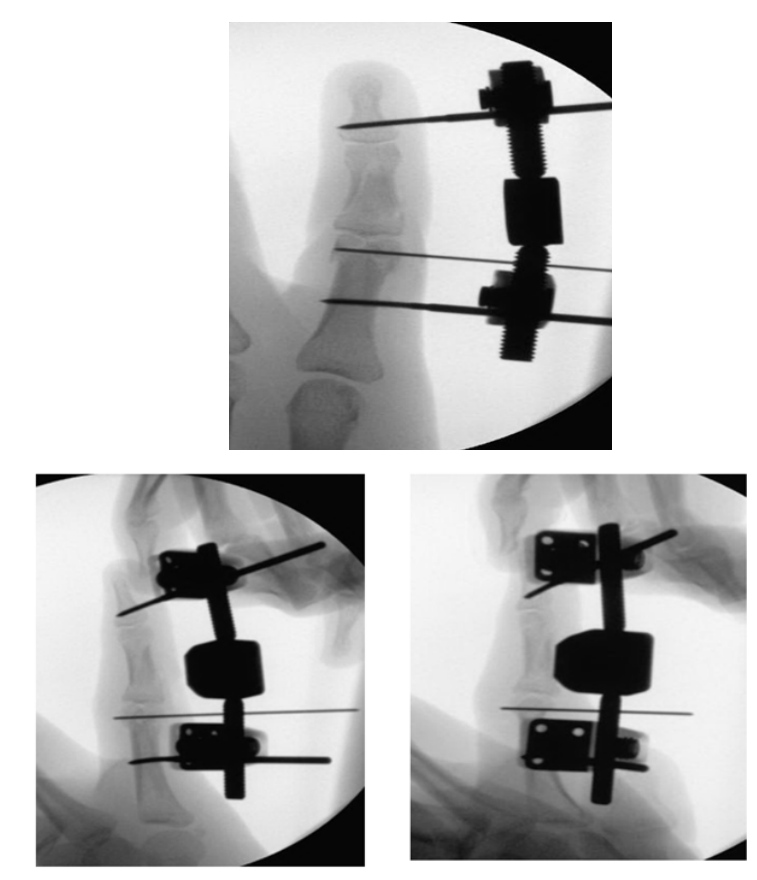

Figure 2:

\section{Discussion}

Traction power can play a big role in complex comminuted fractures reduction. It should always be considered especially when other options are not that effective or have high morbidity.

\section{References}

1) https://www.indiamart.com/aceorthocare/orthopedic-fixators. html\#tubular-external-fixator. 